\section{Effect of Plant Growth Regulators and Fungicides on Huanglongbing-related Preharvest Fruit Drop of Citrus}

\author{
Leo G. Albrigo ${ }^{1,3}$ and Ed W. Stover ${ }^{2}$
}

AdDitional InDEX wORDs. PGR, GA, 2,4-D, strobilurin fungicides, sweet orange, grapefruit, murcott

SuMmARY. The severe citrus (Citrus sp.) disease Huanglongbing (HLB), associated with Candidatus Liberibacter asiaticus, has resulted in widespread tree decline in Florida and overall citrus production is now the lowest it has been in 50 years. More than $\mathbf{8 0 \%}$ of Florida citrus trees are HLB affected, and most growers attempt to sustain production on infected trees through good asian citrus psyllid (Diaphorina citvi) control and enhanced fertilization and irrigation management. Although production appears to benefit from these treatments, preharvest fruit drop is considerably greater than on uninfected trees. U.S. Department of Agriculture (USDA) data indicate that Florida statewide fruit drop has increased by $10 \%$ to $20 \%$ of the entire crop in the last three growing seasons, essentially doubling the historical levels. Extensive research is underway to identify solutions to HLB, but it is essential to maintain production on existing trees to sustain the industry in the near term. For decades, several plant growth regulators (PGRs) have been labeled to reduce preharvest fruit drop in commercial citrus. Trials of these materials, other nonlabeled PGRs, and some fungicides were conducted in two seasons to determine if fruit drop could be reduced. Randomized complete block design experiments were established using four to six replications of four- to six-tree groups as experimental units, blocked spatially. In 2013-14, sprays of gibberellic acid (GA), 2,4-dichlorophenoxyacetic acid (2,4-D), 1-naphthaleneacetic acid (NAA), S-abscisic acid (S-ABA), aminoethoxyvinylglycine (AVG), and 1-methylcyclopropene (1-MCP) were applied once or twice alone or in some combinations at standard rates to trees in various mature blocks of 'Valencia' and 'Pineapple' sweet orange (Citrus sinensis), 'Star Ruby' grapefruit (Citrus paradisi), or 'Murcott' tangor (Citrus reticulata $\times$ C. sinensis) in central Florida in the Indian River area. Only 1 of the 10 individual trials had treatments with significantly lower drop rates than controls; and when pooled across all experiments, GA + 2,4-D reduced number of fruit dropped per tree $4 \%$, but only at $P=0.10$. NAA, S-ABA, AVG, and $1-M C P$ had no effect and were not used the following year. Starting in 2014, treatments were initiated earlier in the season with greater effort to minimize variability: GA; 2,4-D; GA + 2,4-D; a natural GA, indolebutyric acid, cytokinin mix; and strobilurin fungicides were applied to 22 mature blocks of 'Hamlin' and 'Valencia' sweet orange trees. In 2014-15, only three of the 11 individual 'Hamlin' trials and one of the 11 'Valencia' trials included a treatment with significant drop reduction compared with controls. However, when all the tests on 'Hamlin' were pooled, there was a significant 5\% reduction in total crop drop for GA + 2,4-D and significant reductions with many of these PGRs alone, but in only one case with fungicide treatments. When all tests on 'Valencia' were combined, 2,4-D reduced drop significantly but only by $2 \%$ of the total crop ( $14 \%$ drop vs. $16 \%$ drop), but fruit drop in 'Valencia' blocks was near the historical average in control trees. Soil conditions and tree conditions were similar across all test sites and there were no apparent relationships between product efficacy and observed tree condition or any other grove characteristics. In addition, four 'Hamlin' and four 'Valencia' blocks were treated with 1/ 4 rates of 2,4-D + 6-benzyladenine every 45 days during the growing season (six sprays) and three of the eight individual trials showed significant reductions in drop: when pooled, these treatments reduced drop by 3\% in 'Valencia' and 6\% in 'Hamlin'. At this time, PGRs cannot be recommended as a consistent way to reduce fruit drop related to HLB, but further work needs to be conducted to refine the most promising treatments. of Florida citrus trees are infected, and statewide production is the lowest it has been in 50 years. Along with tree decline and reduced cropping, preharvest fruit drop of citrus (Fig. 1) has become more severe (Table 1). The USDA (2015) estimated preharvest fruit drop at $18 \%$ and $23 \%$ of the total crop for early-midseason (E-M) sweet orange cultivars (mainly Hamlin, Midsweet, and Pineapple) and $22 \%$ and $31 \%$ for 'Valencia' sweet oranges for the 2012-13 and 2013-14 seasons, respectively. Except for a small reduction in 'Valencia', drop was similar in the 2014-15 season. Over the three seasons previous to 2012-13 when HLB was less severe, average preharvest drop estimates ranged from $9 \%$ to $11 \%$ for both E-M and 'Valencia'. This recent $10 \%$ to $20 \%$ increase in HLBassociated preharvest drop translates into additional fruit losses worth over $\$ 150$ million annually (L.G. Albrigo, unpublished data).

Citrus fruit drop is related to the formation of an abscission zone near the stem end of the fruit that causes fruit to detach from the stem. This abscission zone is usually stimulated to develop by ethylene, which causes upregulation of cell wall-dissolving enzymes in the abscission zone as fruit are nearly mature (Goren and Huberman, 1976). Stress factors (like drought stress and possibly HLB) can also lead to increased ethylene production in plants including citrus. This premature ethylene production can lead to increased preharvest fruit drop. The synthetic auxin, 2,4-D, has been shown to inhibit upregulation of these cell wall enzymes and can reduce preharvest fruit drop in healthy citrus trees (Goren and Huberman, 1976). The product Citrus Fix $^{\mathrm{TM}}$ (AMVAC, Los Angeles, CA) with the active ingredient 2,4-D has long been registered for use in citrus, specifically to reduce preharvest drop.

Studies of HLB-infected trees indicate that root systems are debilitated
$\mathrm{H}$ uanglongbing has become endemic in Florida, with current estimates that $80 \%$ to $90 \%$

${ }^{1}$ University of Florida, IFAS, Citrus Research and Education Center, Lake Alfred, FL 33850

${ }^{2}$ U.S. Department of Agriculture, Agricultural Research Service, U.S. Horticultural Research Laboratory, 2001 South Rock Road, Fort Pierce, FL 34945

${ }^{3}$ Corresponding author. E-mail: albrigo@ufl.edu.

\begin{tabular}{llll}
\hline $\begin{array}{l}\text { Units } \\
\begin{array}{l}\text { To convert U.S. to SI, } \\
\text { multiply by }\end{array}\end{array}$ & U.S. unit & SI unit & $\begin{array}{l}\text { To convert SI to U.S., } \\
\text { multiply by }\end{array}$ \\
\hline 0.4047 & $\mathrm{acre}(\mathrm{s})$ & $\mathrm{ha}$ & 2.4711 \\
3.7854 & $\mathrm{gal}$ & $\mathrm{L}$ & 0.2642 \\
40.7458 & $\mathrm{gal} / \mathrm{ft}^{2}$ & $\mathrm{~L} \cdot \mathrm{m}^{-2}$ & 0.0245 \\
0.4536 & $\mathrm{lb}$ & $\mathrm{kg}$ & 2.2046 \\
28.3495 & $\mathrm{oz}$ & $\mathrm{g}$ & 0.0353 \\
$\mathrm{l}$ & $\mathrm{ppm}$ & $\mu \mathrm{L} \cdot \mathrm{L}^{-1}$ & 1
\end{tabular}




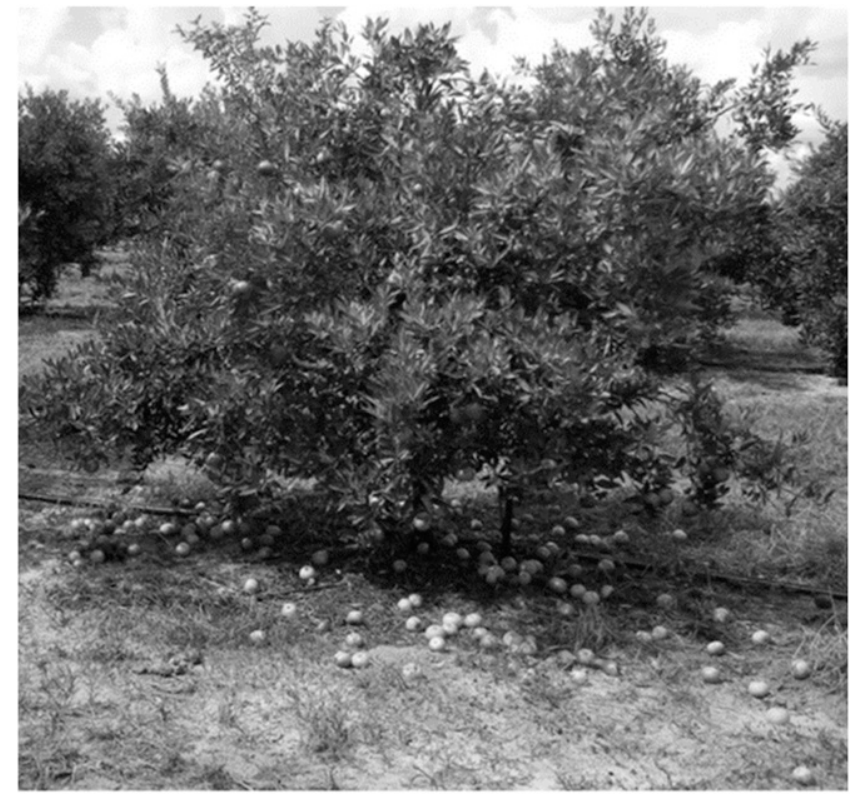

Fig. 1. Extreme preharvest drop example in Florida sweet orange block showing the effect of Huanglongbing disease.

Table 1. Preharvest fruit drop as reported by USDA (2015) for Florida citrus types for the crop seasons indicated.

\begin{tabular}{lcccc}
\hline & \multicolumn{4}{c}{ Fruit drop (\%) } \\
\cline { 2 - 5 } Season & $\mathbf{2 0 0 9 - 1 2}$ & $\mathbf{2 0 1 2 - 1 3}$ & $\mathbf{2 0 1 3 - 1 4}$ & $\mathbf{2 0 1 4 - 1 5}$ \\
\hline Oranges & & & & \\
$\quad$ Early midseason & $9-11$ & 18 & 23 & 31 \\
$\quad$ Late season & $9-11$ & 22 & 31 & 25 \\
Grapefruit & & 18 & 27 & 26 \\
\hline
\end{tabular}

at an early stage (Johnson et al., 2014) and the roots of mature trees are deficient in carbohydrates for normal function (Etxeberria et al., 2009) thus leading to a limited, stressed root system. Water stress has been shown to increase 1-aminocyclopropane-1carboxylic acid in roots, which is then transported to leaves and fruit generating ethylene (Iglesias et al., 2007). Gibberellic acid inhibits this process (Iglesias et al., 2007) and has been used commercially along with 2,4-D to extend the harvest season by delaying peel senescence and retaining fruit on the tree (Ali-Dinar et al., 1976; Ferguson et al., 1982). Thus, auxins and other plant hormones such as GA affect citrus physiology and the effects of endogenous plant hormones can be mimicked by PGRs. Measurement of ethylene levels in symptomatic fruit on trees at early stages of HLB did not indicate elevated ethylene levels, but these trees were not evaluated for reduced root systems nor water stress (Rosales and Burns, 2011).
Studies in the 2013-14 and 2014 15 seasons were funded by the USDA Specialty Crop Research Initiative block grant program through the Florida Department of Agriculture and Consumer Services, the Citrus Research and Development Foundation, several agricultural chemical companies, and supported by many Florida citrus growers. These studies were intended to provide information about citrus physiological and horticultural changes in response to HLB that could help to determine ways to reduce preharvest fruit drop. One possibility was that some PGRs or other production practices could reduce preharvest fruit drop that has been associated with HLB.

We have demonstrated that declining HLB-affected trees experience more drought stress than healthy appearing trees (L.G. Albrigo, unpublished data). Furthermore, more affected trees tend to have higher percentage fruit drop rates than healthy appearing trees, supporting the idea that GA along with 2,4-D would be good candidates to reduce preharvest fruit drop along with possibly other PGR-related products. A grower comparison reported in 2014 (Consolidated Citrus LP, unpublished data) suggested that the strobilurin fungicide Headline might reduce preharvest drop associated with HLB disease, and therefore we included this treatment as well. Here we report the PGR trials as they influenced preharvest fruit drop.

\section{Materials and methods}

Plant growth regulator trials to evaluate effects on HLB-related, preharvest fruit drop were started in Fall 2013. Additional tests were initiated with spray treatments in Jan.-Feb. 2014 on late maturing 'Valencia' trees. New trials were applied in the 2014-15 season. Trials were primarily on commercial grower farms and applied by hand gun from a trailermounted sprayer, but a few tests were applied with commercial speed sprayer by growers. A total of 10 tests were carried out in 2013-14 and another 26 tests in 2014-15. These trials were primarily in citrus blocks representative of the industry with routine-enhanced nutritional applications to improve the performance of HLB-affected trees. In the 2 years of trials, the untreated 'Valencia' control trees had drop rates of $39 \%$ in $2013-$ 14 and $16 \%$ in $2014-15$. These compare with $31 \%$ and $25 \%$ for statewide averages (Table 1). For 'Hamlin' in 2014-15, our test sites averaged 30\% preharvest drop for the untreated controls, whereas statewide the USDA data were $31 \%$ preharvest dropped fruit. This indicates that our test sites were fairly representative of the statewide percentage drop rates, except that our drop rates for controls were markedly below state averages for 'Valencia' in 2014-15.

In 2013-14, materials tested included $20 \mathrm{~g} /$ acre GA (ProGibb; Valent, Libertyville, IL), $15 \mathrm{~g} /$ acre 2,4-D (Citrus Fix ${ }^{\mathrm{TM}}$; AMVAC), $38 \mathrm{~g} /$ acre NAA (PoMaxa; Valent), $20 \mathrm{~g} /$ acre $S$ ABA (Protone; Valent), $15 \mathrm{~g} /$ acre AVG (Retain; Valent), and $1 \mu \mathrm{L} \cdot \mathrm{L}^{-1}$ 1-MCP (29 gal/acre oil emulsion). Except for 1-MCP, materials were hand sprayed at $\approx 1 \mathrm{gal} /$ tree (125 gal/acre) in late September and October to a 'Star Ruby' grapefruit, 'Murcott' tangor, 'Pineapple' 
sweet orange, and four 'Valencia' sweet orange blocks. In late January, three other 'Valencia' blocks were sprayed once. Except for two tests, a randomized block design with four plots of four record trees/treatment was used. In two 'Valencia' tests, four plots of three healthier trees and three moderate-decline-stage trees were used per treatment.

In 2014-15, GA and 2,4-D again were tested at several locations as well as a natural GA, indolebutyric acid, cytokinin mix [94 g/acre a.i. (Ascend ${ }^{\mathrm{TM}}$; Winfield, River Falls, WI)], a strobilurin fungicide pyraclostrobin [88 g/ acre a.i. (Headline ${ }^{\mathrm{TM}}$; BASF, Research Triangle Park, NC)], and four tests included other strobilurins, trifloxystrobin [48 g/acre a.i. $\left(\mathrm{Gem}^{\mathrm{TM}}\right.$; Bayer CropScience, Research Triangle Park, $\mathrm{NC})$, azoxystrobin [88 g/acre a.i. (Abound $^{\mathrm{TM}}$; Syngenta Crop Protection, Greensboro, NC)], and fluxapyroxad + pyraclostrobin [44 g/acre a.i. (Priaxor $\left.\left.{ }^{\mathrm{TM}} ; \mathrm{BASF}\right)\right]$. In addition, trials were conducted with $1 / 4$ rates of 2,4-D + 6-benzyladenine (6-BA) [75 g/acre a.i. (MaxCel ${ }^{\mathrm{TM}}$; Valent)] applied to five 'Hamlin' and five 'Valencia' sites every $45 \mathrm{~d}$ during the growing season (six total sprays).

In 2013-14, 2,4-D and GA treatments tended to show numerically reduced drop compared with unsprayed controls, but due in part to high tree-to-tree variability, few significant differences occurred. In an attempt to overcome this variability plot sizes were increased to six or eight record trees per experimental unit in 2014-15.

In 2014-15, treatments hypothesized to reduce preharvest fruit drop in HLB-infected sweet oranges were applied at numerous sites. Experimental units were groups of six adjoining trees and treatments along with controls were blocked spatially. A few large plot sites had control plots specified for each treatment type as trees available were not suited to a single experiment with all treatments.

Data were collected on fruit per tree before treatment application and for accumulated drop. Fruit drop counts were made every 2 to 3 weeks from 27 Oct. 2014 to 30 Jan. 2015 in 'Hamlin' trials and 4 Nov. 2014 to 23 Apr. 2015 in 'Valencia' trials. Similar drop counts were made in 2013-14.
Because of heterogeneity in HLB symptoms, trees were scored as lightly (rated one) or moderately (rated three) affected by HLB before treatment in 2014-15. Analysis indicated that there were statistically significant differences in response variables associated with the HLB ratings. The number of trees with each score varied within the six-tree plots, so for each plot, the means were calculated separately for "lightly" and for "moderately" affected trees in each plot and then averaged to reduce bias. These adjusted means for each six-tree plot were subjected to statistical analyses. This process was less useful in 2013-14 because of smaller four-tree plots.

The response variables assessed were mean number of fruit dropped per tree and percentage of total fruit which dropped. We also analyzed the fruit per tree before treatment application associated with each treatment. All data were analyzed using the KruskalWallis nonparametric test. Each site was assessed as an individual experiment. In retrospect, more experimental units should have been used at each site. The numbers of fruit per tree were often statistically significantly different between treatments, but regression indicated that $r^{2}$ was high for the relationship between total fruit per tree and number of fruit dropped per tree ('Hamlin': $r^{2}=0.33$, $P \leq 0.001)$ but $r^{2}$ was quite low for the relationship between total fruit per tree and percentage of fruit dropped per tree ('Hamlin': $r^{2}=0.0074$, $P=0.18)$.

Since the same treatments were used at multiple treatment sites, it was possible to pool these data for greater power in determining treatment effects. All analyses included the associated controls for the treatments analyzed. For pooled analysis, block designation included the site and block for each site. Combined GA + 2,4-D treatments were analyzed alone, and grouped with GA treatments, and also grouped with 2,4-D treatments in some analyses.

\section{Results and discussion}

In 2013-14, only one of 10 individual trials had a significant reduction in fruit drop for a treatment, with 2,4-D reducing the proportion of total crop dropped by $4.6 \%$ compared with the control (data not shown).
For pooled tests, GA + 2,4-D and 2,4-D alone numerically reduced drop $4.5 \%$ and $3.7 \%$, respectively, but were not statistically significant (data not shown). AVG, NAA, S-ABA, and 1-MCP did not reduce preharvest fruit drop even numerically in 201314 (data not shown) and were not included in the 2014-15 tests.

Because of more promising results with 2,4-D and GA, PGR tests were continued in 2014-15, with plot size increased to six or eight record trees per experimental unit. In 2014-15, the fungicide Headline and Ascend, a product containing three PGRs, were included but seldom significantly reduced fruit drop (Tables 2 and 3). Two other strobilurin fungicides, Gem and Abound, were tested and showed no effect (data not shown). GA, 2,4-D, and their combination were applied at 12 locations and numerically reduced drop five, four, and six times, respectively, with only five cases overall that were significant (individual data not shown). Most of the significant reductions in drop in 2014-15 were in 'Hamlin' and a grapefruit trial (data not shown), but control drop rates were nearly twice as high in the 'Hamlin' compared with our 'Valencia' trials [Table 2 vs. Table 3 (data and statistics for individual trials not shown)].

Since differences between treatments were generally small and variability was still large in the 2014-15 season, trials were pooled for like treatments and the data were analyzed using the Kruskal-Wallis nonparametric test. In 'Hamlin' trials (Table 2), percent fruit drop differences were significant for tree condition $(3 \%)$ and the GA $(4 \%), 2,4-D$ $(3 \%)$, and GA $+2,4-\mathrm{D}(5 \%)$ treatments reducing drop as indicated compared with their controls. The low concentration treatment of 2,4-D + 6-BA reduced drop $6 \%$ compared with the control. Directly comparing GA and 2,4-D alone with the combination of $\mathrm{GA}+2,4-\mathrm{D}$ in a composite of the four trials, which included all these treatments indicated that the combination reduced drop 7\% over the control and was superior to PGR applied alone in number of fruit dropped per tree.

'Valencia' tests in 2014-15 had much lower drop rates than 'Hamlins', $16 \%$ vs. $26 \%$ drop in controls, and significant differences for pooled data 
Table 2. Statistical analyses for pooled experiments on 'Hamlin' sweet orange blocks having the same treatments in $2014-15$.

Comparisons for gibberellic acid (GA) and/or 2,4-dichlorophenoxyacetic acid (2,4-D), strobilurin fungicides, or a combination of three plant growth regulators (PGR) are against their appropriate controls.

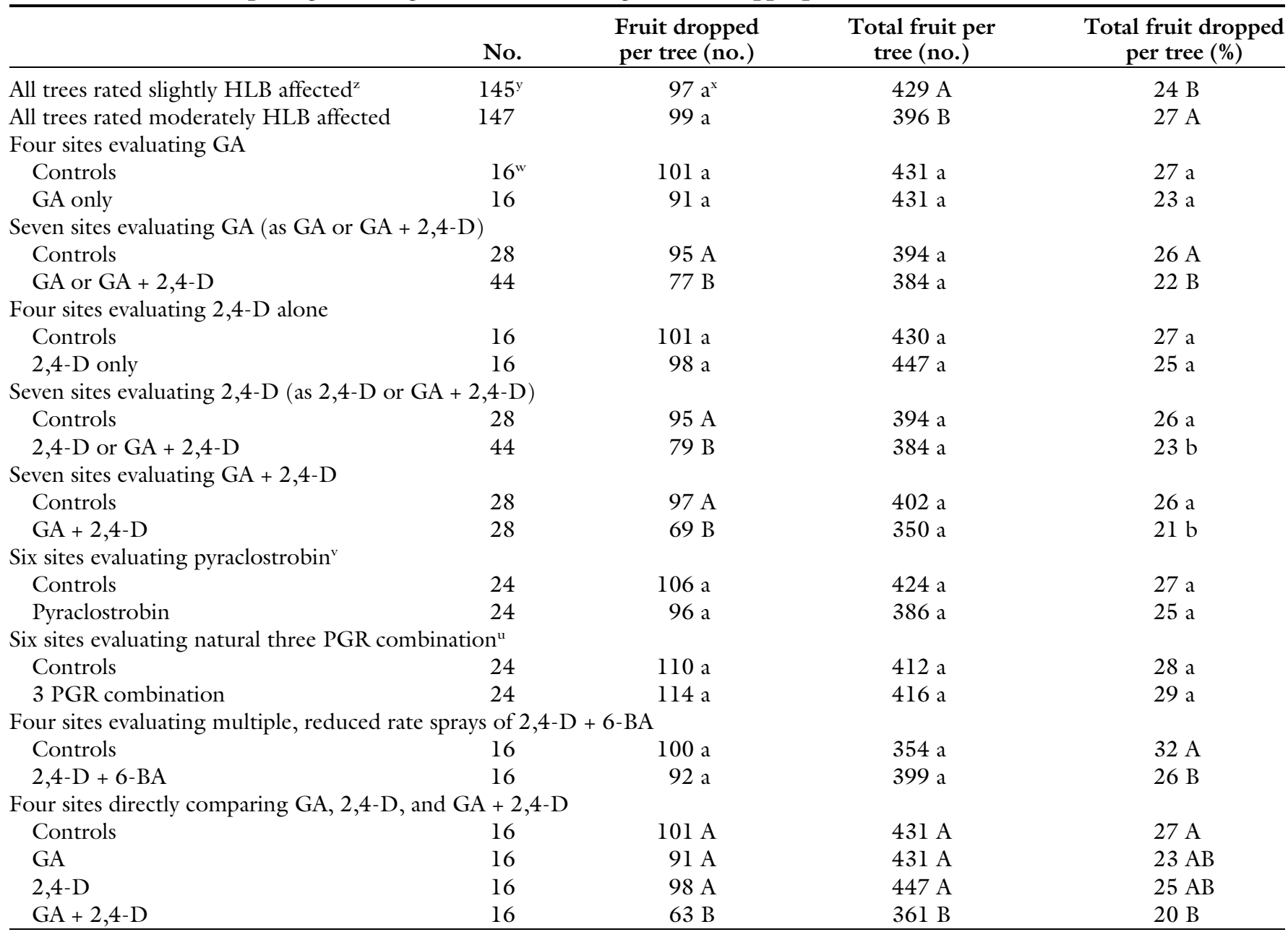

${ }^{\mathrm{z}} \mathrm{HLB}=$ Huanglongbing disease of citrus.

yExperimental units were one to six trees (usually three) within a six-tree group, which had the same HLB severity score.

${ }^{x}$ Within a comparison column (bounded by horizontal lines above and below) means followed by the same letter are not statistically different at the $P=0.05$ level for capital

letters or at the $P=0.10$ level for lower case letters. Data analyzed by Kruskal-Willis nonparametric test.

"Experimental units six-tree groups with four record trees.

"Pyraclostrobin (Headline; BASF, Research Triangle Park, NC).

"Natural product with three PGRs (Ascend; Winfield, River Falls, WI).

were fewer and had smaller differences from the controls (Table 3 ). Trees scored as "lightly HLB affected" vs. "moderately HLB affected" were only $2 \%$ different in drop, whereas only $2,4-\mathrm{D}$ single regular concentration $(2 \%$ difference in drop from control) and 2,4-D + 6-BA frequent low concentration ( $3 \%$ drop difference) were significantly lower than the controls. Over the past two seasons, similar tests of December 2,4-D sprays on 'Valencia' trees in Florida also reduced preharvest fruit drop only $\approx 40 \%$ of the time with an average reduction in drop from $5 \%$ to $28 \%$ (Syvertsen et al., 2015). The sites with significant results were not always the same between the 2 years. This further supports the difficulty in determining why the treatments worked in some locations and not others.

Even though numerical and significant differences occurred at low frequency, less than $40 \%$ and $10 \%$ of tests, for 'Hamlin' and 'Valencia', respectively, the pooled data suggest that over a larger treated area, that might overcome some local soil or tree conditions, 2,4-D + GA may reduce fruit drop by $5 \%$ of the crop, cutting in half the apparent HLB-induced drop increases. At 400 boxes/acre $(90 \mathrm{lb} /$ box) yields, this could return a value of $\$ 250 /$ ha before costs of materials. Most growers are routinely spraying for the HLB psyllid vector and tank mixing would make additional spraying costs negligible.
However, no positive response was observed in many of the test sites and at this time PGRs cannot be recommended as a consistent way to reduce fruit drop related to HLB. Test sites were similar in soil and production practice conditions and essentially all trees had some level of HLB making it difficult to identify tree condition or grove characteristics that related to efficacy in drop reduction that might account for success or failure of a PGR application for preharvest fruit drop reduction. Good nutrition and irrigation with frequent applications (perhaps daily through the fall for 'Hamlin', and through the spring for 'Valencia') may be better ways to reduce preharvest 
Table 3. Statistical analyses for pooled experiments on 'Valencia' sweet orange blocks having the same treatments in 201415. Comparisons for gibberellic acid (GA) and/or 2,4-dichlorophenoxyacetic acid (2,4-D), strobilurin fungicides, or a combination of three plant growth regulators (PGR) are against their appropriate controls.

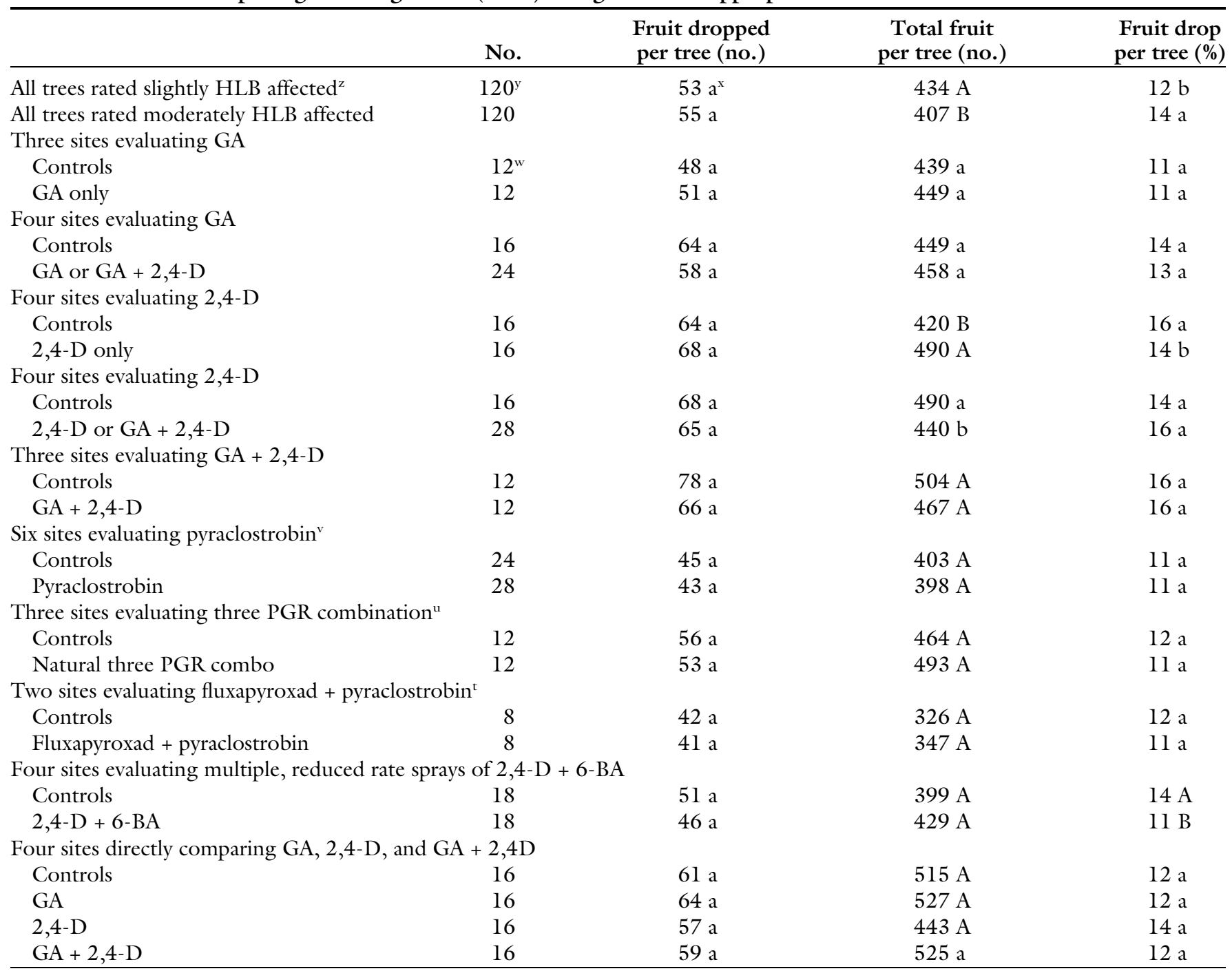

${ }^{\mathrm{z}} \mathrm{HLB}=$ Huanglongbing disease of citrus.

'Experimental units were one to six trees (usually three) within a six-tree group, which had the same HLB severity score.

${ }^{x}$ Within a comparison column (bounded by horizontal lines above and below) means followed by the same letter are not statistically different at the $P=0.05$ level for capital letters or at the $P=0.10$ level for lower case letters. Data analyzed by Kruskal-Willis nonparametric test.

"Experimental units six-tree groups with four record trees.

vPyraclostrobin (Headline; BASF, Research Triangle Park, NC).

"Natural product with three PGRs (Ascend; Winfield, River Falls, WI).

${ }^{t}$ Fluxapyroxad + pyraclostrobin (Priaxor, BASF).

fruit drop. Even so, the urgency of enhancing cropping in Florida citrus in the face of HLB suggests the need for further work to refine the most promising PGR treatments and their interactions with location factors and enhanced cultural practices to make these PGR treatments more reliable.

\section{Literature cited}

Ali-Dinar, H.M., A.H. Krezdorn, and A.J. Rose. 1976. Extending the grapefruit harvest season with growth regulators. Proc. Florida State Hort. Soc. 89:4-6.
Etxeberria, E., P. Gonzalez, D. Achor, and G. Albrigo. 2009. Anatomical distribution of abnormally high levels of starch in HLB-affected Valencia orange trees. Physiol. Mol. Plant Pathol. 74:76-83.

Ferguson, L., M.A. Ismail, F.S. Davies, and T.A. Wheaton. 1982. Pre- and postharvest gibberellic acid and 2,4dichlorophenoxyacetic acid applications for increasing storage life of grapefruit. Proc. Florida State Hort. Soc. 95:242245.

Goren, R. and M. Huberman. 1976. Effects of ethylene and 2,4-D on the activity of cellulase isoenzymes in abscission zones of the developing orange fruit. Physiol. Plant. 37:123-130.

Iglesias, D.J., M. Cercos, J.M. ColmeneroFlores, M.A. Naranjo, G. Ríos, E. Carrera, O. Ruiz-Rivero, I. Lliso, R. Morillon, F.R. Tadeo, and M. Talon. 2007. Physiology of citrus fruiting. Braz. J. Plant Physiol. 19:333-362.

Johnson, E.G., J. Wu, D.B. Bright, and J.H. Graham. 2014. Association of 'Candidatus Liberibacter asiaticus' root infection, but not phloem plugging with root loss on huanglongbing-affected trees prior to appearance of foliar symptoms. Plant Pathol. 63:290-298. 


\section{Research Reports}

Rosales, R. and J.K. Burns. 2011. Phytohormone changes and carbohydrate status in sweet orange fruit from huanglongbing-infected trees. J. Plant Growth Regulat. 30:312-321.
Syvertsen, J.P., T. Minter, H. Yonce, and W. Bandaranayake. 2015. A single application of 2,4-D can decrease preharvest fruit drop in HLB-affected 'Valencia' orange trees. Proc. Florida State Hort. Soc. (In press).
U.S. Department of Agriculture (USDA). 2015. Citrus fruit size and drop 2014-15 report. 4 Nov. 2015. <http://www.nass. usda.gov/Statistics_by_State/Florida/ Publications/Citrus/index.php $>$. 